\title{
A Millennium-Long Tree-Ring Chronologies Koksu and Tara on Altay
}

\author{
Vladimir S. Myglan*, \\ Valentin V. Barinov and Andrey N. Nazarov \\ Siberian Federal University \\ 79 Svobodny, Krasnoyarsk, 660041, Russia
}

Received 20.11.2014, received in revised form 06.12.2014, accepted 16.08.2015

The work presents two new 1000-year tree-ring chronologies: Tara (AD 795-2011, the South Chui Range) and Koksu (AD 588-2011, the Katun Range). The calculation of the response function shows that the dominating factor affecting the radial growth of the tree-ring chronology Koksu is June and July temperatures and for Tara it is June temperature. The strong correlation between Koksu chronology and records of meteorological stations placed in the Northern Mongolia and China at a distance of 300 or more kilometers from the sites of sample collection illustrates that the chronology reflects summer temperature changes at least on a regional scale. At the same time Tara chronology is weakly sensitive to changes in summer temperatures and may be used for dating of geomorphologic, historical and climatic events. The analysis of abnormal structures and missing rings detected on the samples revealed the dates of extreme events for each chronology.

Keywords: dendrochronology, treeline, tree-ring growth anomaly, missing ring, climate extremum, Altai.

DOI: $10.17516 / 1997-1389-2015-8-3-319-332$.

(c) Siberian Federal University. All rights reserved

* Corresponding author E-mail address: dend_ro@mail.ru 


\title{
Построение тысячелетних
}

\section{древесно-кольцевых хронологий Koksu и Tara}

\section{для территории Алтая}

\author{
В.С. Мыглан, В.В. Баринов, А.Н. Назаров \\ Сибирский федеральный университет \\ Россия, 660041, Красноярск, пр. Свободныий, 79
}

В статье представлень две новые тысячелетние древесно-кольцевые хронологии по лиственнище сибирской (Larix sibirica Ldb.) на верхней границе леса: Tага (для периода с 795 по 2011 г., Южно-Чуйский хребет) и Koksи (для периода с 588 по 2011 г., Катунский хребет). Расчет функичи отклика показал, что основное воздействие на радиальньий прирост древесно-кольцевой хронологии Koksu оказывают температуры июня и июля, а древесно-кольцевой хронологии Тага - только июня. Древесно-кольцевая хронология Кокsи характеризуется наличием устойчивой и значимой связи с рядами наблюдений метеостанций, расположенных в Северной Монголии и Китае, т.е. она отражает изменчивость раннелетней температуры как минимум регионального масштаба. Древесно-кольцевая хронология Тага менее чувствительна к изменению летних температур и может быть пригодна для дендроиндикации геоморфологических, исторических и климатических событий (определение времени повреждения деревьев в ходе обвалов, селей, датировка древесинь археологических памятников и т.п.). Анализ выявленных аномальных структур и выпавших колец на образцах позволил определить даты экстремальных событий для каждой хронологии.

Ключевые слова: дендрохронология, верхняя граница леса, патологии структурь годичного кольциа, выпавиие кольц̧а, климатические аномалии, Алтай.

\section{Введение}

Древесные кольца являются косвенным источником палеоклиматической информации с высоким погодичным (сезонным) разрешением, позволяющим выполнять реконструкции региональных климатических изменений за тысячелетние временные отрезки (Fritts, 1976). Значительную ценность дендрохронологические исследования представляют для Республики Алтай, где изменчивость прироста древесных растений, в первую очередь лиственницы (Larix sibirica Ldb.) на верхней границе произрастания, содержит сильный климатический (темпера- турный) сигнал, обусловленный кратковременностью вегетационного сезона (Шиятов, 1986; Овчинников, Ваганов, 1999 и др.). В настоящее время для этого региона построено несколько тысячелетних древесно-кольцевых хронологий (ДКХ): 1105-летняя по Актру (Овчинников и др., 2002) и 1896-летняя хронология Jelo (Myglan et al., 2012a) по лиственнице сибирской, 1241-летняя хронология по Актру-Корумду-Маашей (Назаров, Мыглан, 2012) по сосне сибирской (Pinus sibirica Du Tour), которые преимущественно охватывают территорию Северо-Чуйского хребта. В результате нерешенными остаются вопросы, 
связанные с пространственным анализом неоднородности распределения климатических аномалий, погодичной и внутривековой изменчивости ДКХ и пр. на территории Алтая. Представленные в статье новые ДКХ: Koksu (Катунский хребет) и Tara (Южно-Чуйский хребет) существенно расширяют территориальный охват тысячелетними хронологиями Алтайского региона и позволяют ответить на часть поставленных вопросов.

\section{Материалы и методы}

Объектом исследования послужили образцы лиственницы сибирской, отобранные с разновозрастных деревьев и отмерших древесных остатков на двух участках - Koksu и Tara (рис. 1). При отборе образцов для получения хронологий с устойчивым откликом на изменение температуры закладывались участки размером около 2 км² на верхней границе леса (высота 2200-2250 м н.у.м.). Керны отбирали по стандартной методике на высоте
1,3 м (Шиятов и др., 2000), у каждого дерева измеряли высоту, диаметр ствола и другие показатели. Поперечные спилы выпиливали с древесных остатков, сохранившихся на дневной поверхности (курумники, выходы коренных пород и пр.) выше или в пределах современной границы распространения древесной растительности. Положение каждого образца фиксировали с помощью GPS-навигатора (Garmin 60Cx).

Участок Koksu. Маршрутный осмотр верхней границы леса долины р. Коксу показал, что только на заложенном пробном участке фиксируются отдельно стоящие лиственницы возрастом более 500 лет. Место отбора образцов представляет собой субгоризонтальную выровненную поверхность на склоне северной экспозиции, расположенную на расстоянии 1.5-2 км ниже скальной стенки кара, отмечающего центральную часть хребта (рис. 2а). Наличие небольших заросших сфагнумом (Sphagnum L.) водоемов сви-

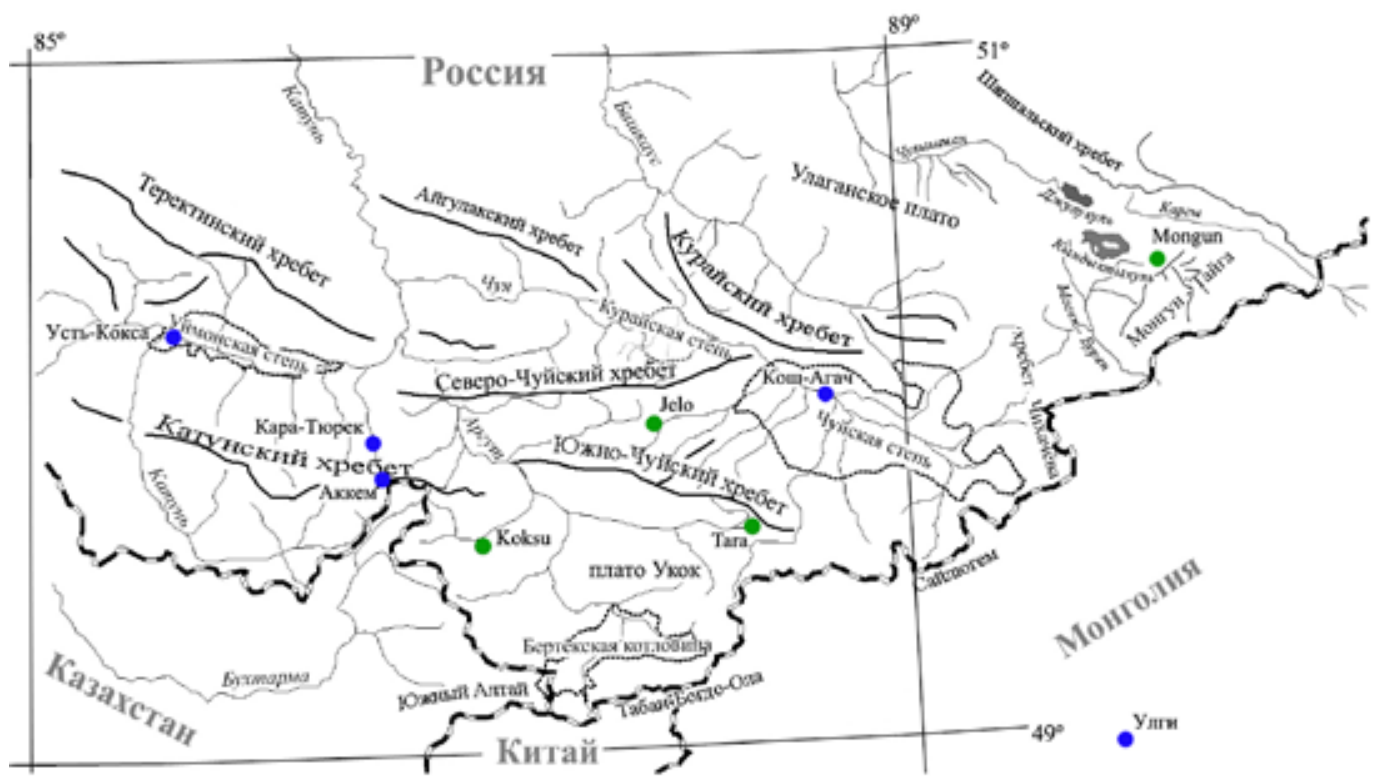

Рис. 1. Орографическая схема Центрального и Восточного Алтая с указанием расположения участков отбора образцов Larix sibirica и метеостанций. Синие точки - положение метеостанций Усть-Кокса, Кара-Тюрек, Ак-Кем, Кош-Агач, Улги, зелёные - древесно-кольцевые хронологии Koksu, Tara, Jelo, Mongun 

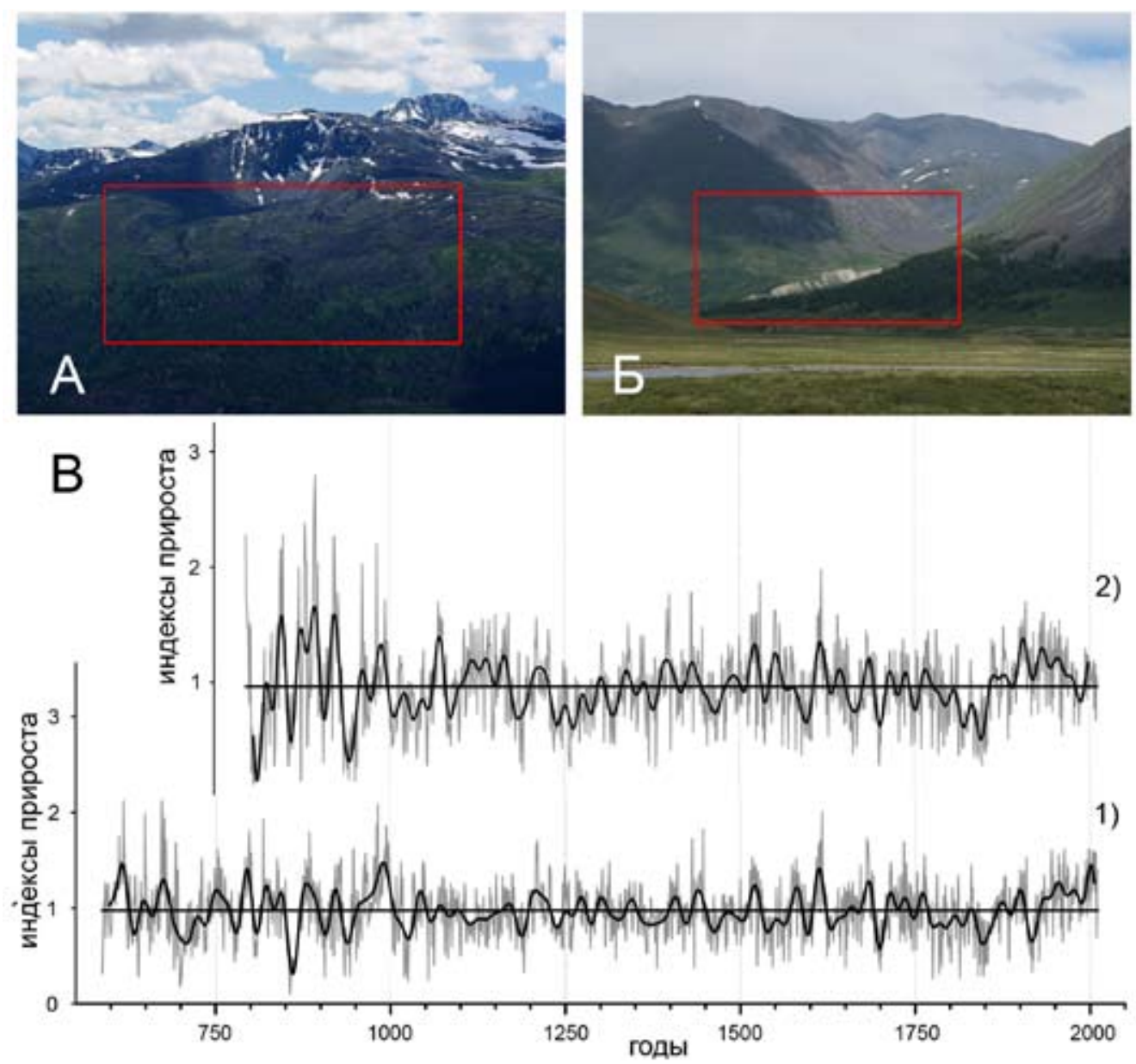

Рис. 2. Общий вид участков отбора образцов в долине рек Коксу (а), Тара (б). Стандартизированные древесно-кольцевые хронологии (в): Tara (1) и Koksu (2). Тонкой линией отображены погодичные, жирной - сглаженные низкочастотным 22-летним фильтром колебания индексов прироста, горизонтальной чертой отмечена средняя арифметическая

детельствует о достаточной увлажненности участка. Сомкнутость древостоя на участке отбора образцов составляет 0.2 (здесь и далее приводится по Мелехову, 1980). Всего с участка было собрано 27 кернов и 22 образца палеодревесины.

Участок Tara. Осмотр верхней границы леса на южных склонах Южно-Чуйского хребта выявил наличие на левом притоке р. Тара локально расположенного участка лиственничного леса (рис. 2б). Лиственница в районе исследования испытывает недостаток влаги, имеет островное распространение и приуро- чена к ручьям, склонам северо-западных экспозиций, дольше сохраняющих снежный покров и влагу (Огуреева, 1980, с. 139-149). Керны отбирались на верхней границе леса в сформировавшемся древостое (сомкнутость 0.6) из-за отсутствия произрастающих выше по склону одиночных экземпляров и групп деревьев. Всего с участка на склоне югозападной экспозиции было взято 29 кернов и 40 спилов палеодревесины.

Камеральная обработка образцов была выполнена по стандартной методике (Шиятов и др., 2000), измерения ширины годич- 
ных колец проводили на полуавтоматической установке «LINTAB» (с точностью 0.01 мм). Датирование измеренных серий было выполнено посредством сочетания графической перекрестной датировки (Douglass, 1919) и кросс-корреляционного анализа в пакете специализированных программ для дендрохронологических исследований DPL (Holms, 1983) и TSAP V3.5 (Rinn, 1996).

Возрастной тренд из древесно-кольцевых серий был удален на основе использования негативной экспоненты и сплайна в две трети от длины индивидуальной серии в программе ARSTAN (Cook, Krusic, 2008). Оценка качества построенной хронологии выполнялась на основе применения традиционных показателей: стандартное отклонение характеризует амплитуду погодичной изменчивости прироста, EPS - чувствительность древеснокольцевой хронологии к изменению внешних факторов (иллюстрирует, как конкретная выборка отражает сигнал целой выборки (популяции или генеральной совокупности)) и RBAR - среднее значение коэффициента корреляции между отдельными древеснокольцевыми сериями (Wigley et al., 1984; Cook, Kairiukstis, 1990).

Для выявления нарушений структуры годичного кольца был проведен визуальный осмотр кернов на микроскопе Stemi 2000-C (Carl Zeiss). Фиксация обнаруженной аномальной структуры (патологической структуры годичного кольца) достигалась путем нанесения отметки на поврежденное годичное кольцо. Для верификации дендрохронологической датировки и исключения ошибки выполнялось повторное измерение участка керна, содержащего это кольцо (20 лет до и 50 лет после), и последующая его перекрестная датировка. При поиске повреждений учитывали следующие типы аномальных структур (Шиятов и др., 2000): морозобойное кольцо (f) - искаженная структура ксилемной ткани, поврежденной заморозком в сезон роста, когда формируются клетки ксилемы; флюктуация древесины (fl) - слой клеток в пределах годичного кольца, который выделяется из соседних слоев по форме, размеру, а также форме и толщине клеточной стенки; светлое кольцо (1) - зона поздней древесины годичного кольца с заметно слабой лигнификацией. Кроме того, нами был выделен отдельный тип нарушения: разлом (с) - это, вероятно, слабо просматривающееся морозобойное кольцо, поврежденные клеточные стенки которого разрываются, не выдержав перепадов температур и механических деформаций ствола при жизни дерева. Рассмотрение дат образования на образцах патологических смоляных ходов (выделенных согласно определению, приведенному в работе Шиятова и др., 2000, с. 53) показало случайный характер их распределения, т.е. отсутствие совпадений, вследствие чего они были исключены из дальнейшего анализа. Выпавшие кольца, полностью отсутствующие на радиальном срезе образца в связи с прекращением деятельности камбиального слоя, были найдены в результате проведения графической перекрестной датировки и кросс-корреляционного анализа. Анализ выпавших колец был проведен отдельно, поскольку в этих случаях невозможно было оценить повреждения клеточной структуры.

Для уменьшения «шума», связанного с учетом аномалий структуры годичного кольца, образовавшихся под действием локальных условий произрастания модельных деревьев, в работе не учитывались аномалии, приходящиеся на первые 20 лет жизни, когда из-за тонкого теплоизоляционного слоя коры деревья получают повреждения даже при наступлении незначительных заморозков в вегетационный период (Быков, 2000). Согласно исследованиям М.А. Гурской и С.Г. Шиято- 
ва (2006), основная часть морозобойных повреждений фиксируется на высоте ствола до 1 м. По этой причине для выделения наиболее сильных заморозков, при которых высота приземного слоя воздуха с отрицательными температурами достигает 4-7 м, керны желательно отбирать на высоте более 1 м от дневной поверхности. За критерий выделения экстремальных событий на участке было принято совпадение дат образования двух и более аномальных структур или выпавших колец в образцах на участке.

В работе были использованы ряды месячных наблюдений за приземной температурой воздуха и количеством осадков с метеорологических станций: «Усть-Кокса» (1940-2013 гг.), «Ак-Кем» (1961-1995 гг.), «Кара-Тюрек» (1940-2013 гг.), «Кош-Агач» (1933-2013 гг.) и «Улги» (1959-2009 гг., Монголия), взятые с сайтов meteo.ru и climexp. knmi.nl. Для выделения региональной составляющей в изменчивости прироста были привлечены построенные для прилегающих территорий тысячелетние ДКХ Jelo (Myglan et al., 2012a) и Mongun (Myglan et al., 2012b).

\section{Результаты и обсуждение}

Путем стандартных процедур по обработке дендрохронологического материала были построены ДКХ Тага протяженностью 1217 лет (для периода с 795 по 2011 г.) и Koksu длительностью 1424 г. (для периода с 588 по 2011 г.) (рис. 2в). Доля выпадающих колец в хронологиях составила менее $1 \%$ от их общего числа. Средняя и максимальная длина индивидуальных серий достигает у ДКХ Tara 294 и 567 лет, Koksu - 349 и 736 лет соответственно. Анализ распределения числа деревьев в древесно-кольцевых хронологиях относительно начала времени их роста показал, что оно неоднородно и демонстрирует тенденцию к снижению количества деревьев по мере продвижения в прошлое (рис. 3). Выделяются три периода, на которые приходится гибель деревьев: середина XIII в., середина XVI - первая половина XVII в. (более выражен на ДКХ Tara, pис. 3б) и вторая половина XVIII - начало XIX в. (больше проявляется на ДКХ Koksu, pис. 3a).

Рассмотрение показателей EPS и RBAR выявило, что обе хронологии пригодны для реконструкции климатических параметров в период с 1100 по 2011 г. (EPS $\geq 0.85$, рис. 3). Для количественной оценки климатического сигнала, содержащегося в хронологии, были рассчитаны функции отклика с рядами инструментальных метеонаблюдений за приземной температурой воздуха (табл. 1). Коэффициенты корреляции индексов прироста ДКХ с осадками имеют невысокие значения и носят случайный характер, поэтому в работе не рассматриваются.

Результаты проведенного анализа показали, что основное воздействие на изменчивость радиального прироста ДКХ Тага оказывает температура июня и в меньшей степени - апреля. Положительное влияние температур июня на прирост лиственницы хорошо известно и отмечается многими исследователями (Шиятов, 1986; Овчинников и др., 2002; Sidorova et al., 2012; Sidorova et al., 2013 и др.). Отрицательный характер связи с апрельскими температурами, вероятно, вызван тем, что высокие среднемесячные температуры апреля ведут к быстрому сходу снежного покрова. К этому времени почвенный слой еще не оттаивает, как следствие, происходит сток талой воды, приводящий в дальнейшем к недостаточному почвенному увлажнению на момент начала вегетационного сезона. Невысокие значения коэффициентов корреляции ДКХ Тara со среднемесячными температурами июня-июля (0.22-0.49) позволяют предположить, что данная хроно- 


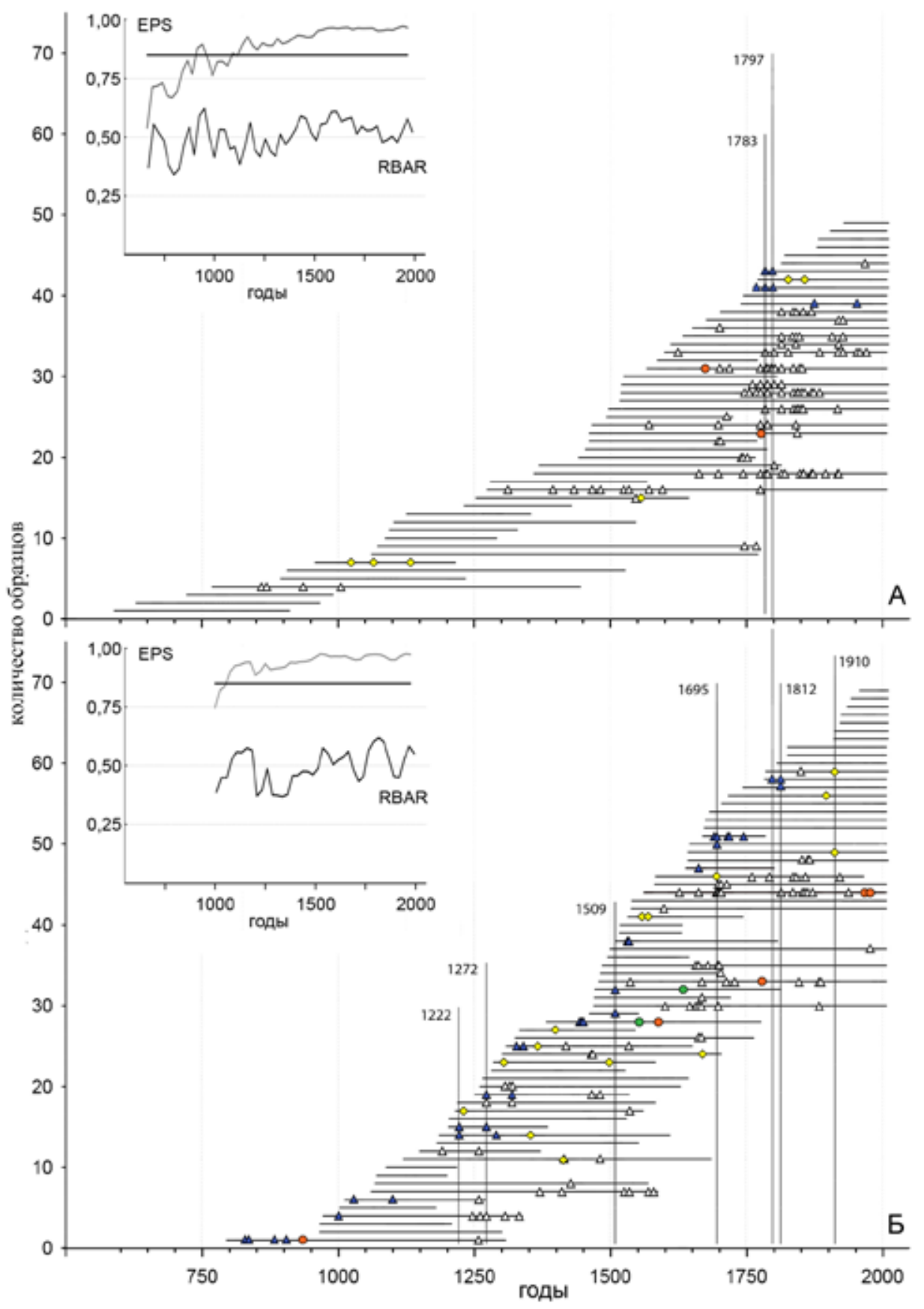

Рис. 3. Ранжирование образцов относительно времени начала их произрастания, показатели EPS и RBAR, распределение выпавших и аномальных колец в ДКX Koksu (A) и Tara (Б). Выпадающие кольца отмечены треугольниками, морозобойные - треугольниками с заливкой, разломы отображены в виде ромбов, светлые кольца обозначены кружками, флюктуации в древесине - кружками с темной заливкой. Вертикальными линиями отмечены годы экстремальных климатических событий 
логия слабо пригодна для выполнения температурных реконструкций и в большей степени может быть использована для выполнения дендроиндикации геоморфологических и исторических событий (установления времени повреждения деревьев в ходе обвалов, селей, датировки древесины археологических памятников и др.).

Корреляционный анализ ДКХ Koksu и рядов инструментальных наблюдений метеостанций показал, что фиксируется положительная значимая связь со среднемесячными температурами с мая по август, при этом основной вклад в радиальный прирост вносят июнь-июльские температуры (табл. 1). Наличие устойчивой значимой связи индексов прироста ДКХ Koksu с данными метеостанций, удаленных на 300 км и более от точки сбора образцов, говорит о том, что данная хронология пригодна для проведения реконструкции раннелетней температуры (объясняет до 50 \% ее изменчивости) и отражает ход летней температуры как минимум регионального масштаба.

Графическое сопоставление изменчивости кривых прироста хронологий Koksu и Tara между собой показало, что их общий ход достаточно хорошо согласован (рис. 4б). Однако в ряде случаев присутствуют явные расхождения в поведении кривых, которым исходя из ранее найденных зависимостей (табл. 1) можно дать качественную характеристику. Так, например, в годы, когда значения прироста у ДКХ Koksu выше по сравнению ДКХ Тara (например, с 1572 по 1589 гг.), можно предположить, что среднемесячная температура весной и в первую половину лета превышала норму, что приводило к более ранним срокам начала вегетационного периода. Когда кривая прироста находится ниже (например, с 1909 по 1926 г.), можно предположить, что эти годы характеризуются поздней весной и холодной первой половиной лета. Наоборот, в периоды с 1100 по 1170 г. и с 1543 по 1562 г., когда кривая прироста ДКХ Tara находится существенно выше, чем у ДКХ Koksu, можно охарактеризовать как годы с поздним наступлением весны (при этом деревья на участке Tara весной и в первую половину лета не испытывали дефицита влаги). В случаях, когда у ДКХ Тага наблюдается падение прироста (1231-1270, 1653-1675, 1979-1995 гг. и др.),

Таблица 1. Коэффициенты корреляции (Пирсона) индексов прироста ДКХ Таra и Koksu co среднемесячными температурами по данным метеостанций

\begin{tabular}{|c|c|c|c|c|c|c|c|c|c|c|}
\hline \multirow{4}{*}{ Месяцы } & \multicolumn{10}{|c|}{ Метеостанции } \\
\hline & \multicolumn{2}{|c|}{ Усть-Кокса } & \multicolumn{2}{|c|}{ Ак-Кем } & \multicolumn{2}{|c|}{ Кара-Тюрек } & \multicolumn{2}{|c|}{ Кош-Агач } & \multicolumn{2}{|c|}{ Улги } \\
\hline & Tara & Koksu & Tara & Koksu & Tara & Koksu & Tara & Koksu & Tara & Koksu \\
\hline & \multicolumn{2}{|c|}{$\mathrm{N}=69$} & \multicolumn{2}{|c|}{$\mathrm{N}=35$} & \multicolumn{2}{|c|}{$\mathrm{N}=65$} & \multicolumn{2}{|c|}{$\mathrm{N}=76$} & \multicolumn{2}{|c|}{$\mathrm{N}=35$} \\
\hline IV & -0.27 & -0.19 & -0.17 & -0.27 & -0.25 & -0.19 & -0.34 & -0.11 & -0.35 & -0.23 \\
\hline $\mathrm{V}$ & 0.12 & 0.33 & 0.19 & 0.32 & 0.12 & 0.32 & 0.02 & 0.22 & -0.14 & 0.18 \\
\hline VI & 0.49 & 0.62 & 0.49 & 0.58 & 0.45 & 0.59 & 0.38 & 0.55 & 0.22 & 0.56 \\
\hline VII & 0.09 & 0.34 & 0.19 & 0.43 & 0.10 & 0.35 & 0.01 & 0.30 & 0.12 & 0.50 \\
\hline VIII & 0.10 & 0.24 & 0.18 & 0.00 & 0.03 & 0.16 & -0.03 & 0.14 & 0.17 & 0.24 \\
\hline VI-VII & 0.40 & 0.64 & 0.48 & 0.69 & 0.39 & 0.65 & 0.29 & 0.57 & 0.22 & 0.65 \\
\hline
\end{tabular}

Примечание: $\mathrm{N}$ - объем использованной выборки, жирным шрифтом выделены значимые коэффициенты корреляции при $\mathrm{p}<0,05$. 


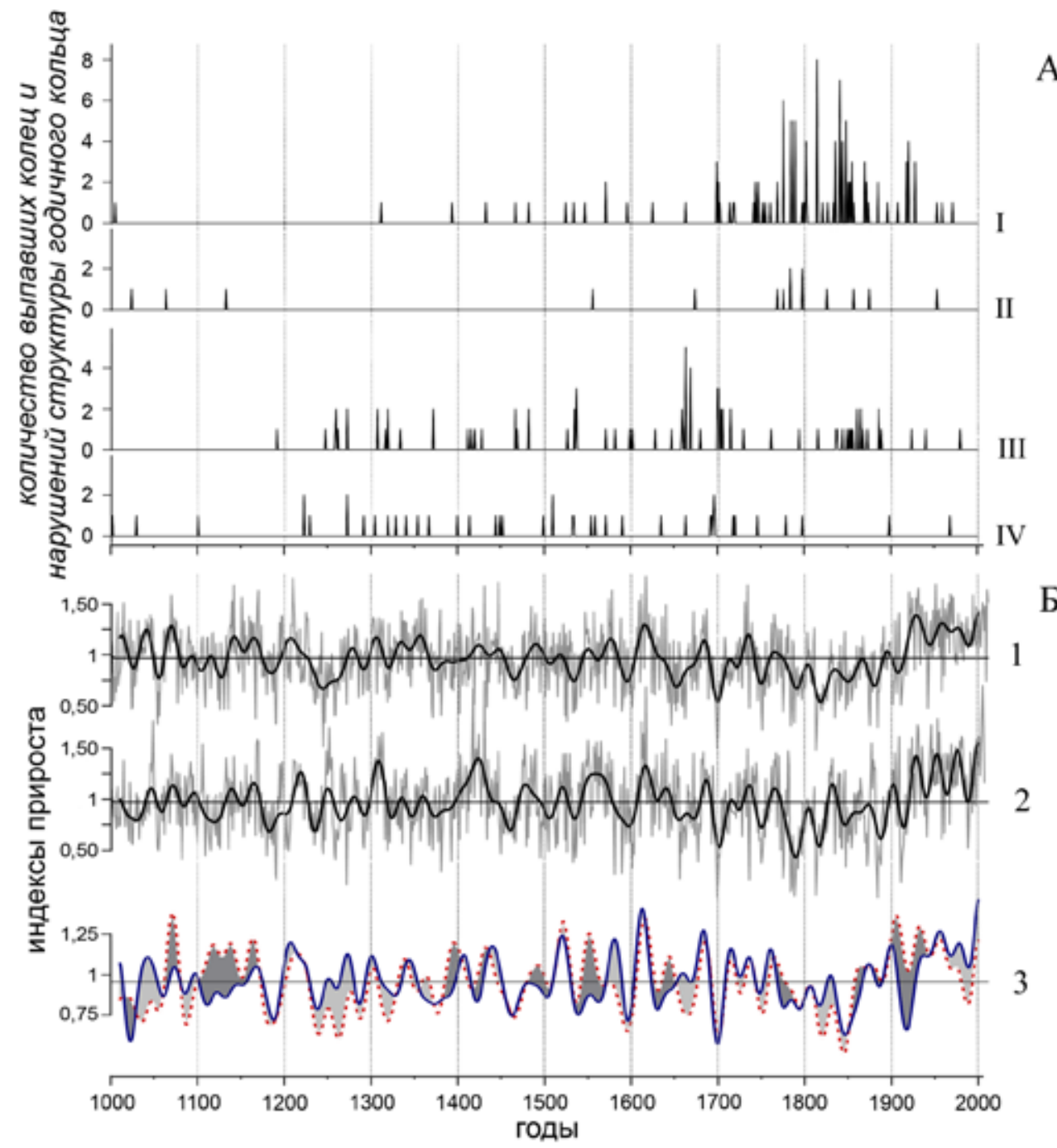

Рис. 4. $\boldsymbol{A}$ - распределение выпавших колец и нарушений в структуре годичного кольца у ДКХ Кoksu (I и II соответственно) и Tara (III и IV соответственно). $\boldsymbol{Б}$ - изменчивость прироста ДКX 1 - Jelo и 2 Mongun, тонкой линией отображены погодичные, жирной - сглаженные низкочастотным 22-летним фильтром колебания индексов прироста; 3 - изменчивость прироста ДКХ Koksu (сплошная линия) и Tara (пунктирная линия), заливкой выделены различия в приросте у хронологий, заложенных на склонах северной и южной экспозиций. Горизонтальной чертой отмечена арифметическая средняя

можно говорить о раннем приходе весны с достаточно засушливой погодой, затронувшей и первую половину лета. Наши предположения хорошо согласуются с информацией об изменениях режима увлажнения на Алтае во второй половине ХХ в. Так, выделенный нами период с засушливой погодой (1979-1995 гг.) хорошо согласуется с данными М.Г. Суховой,
Т.Д. Модиной (2007) о выпадении осадков ниже нормы в 1980-1995 гг.

Для оценки, насколько прирост ДКХ Koksu и Tara отражает региональный сигнал, они были сопоставлены с тысячелетними древесно-кольцевыми хронологиями по Алтае-Саянскому региону Jelo и Mongun (рис. 1, табл. 2). Погодичные значения ин- 
Таблица 2. Коэффициенты корреляции (Пирсона) между погодичным и сглаженными значениями индексов прироста ДКХ Tara, Koksu, Jelo, Mongun

\begin{tabular}{|l|c|c|c|c|c|c|c|}
\hline & Tara & Koksu & Jelo & & Tara & Koksu & Jelo \\
\cline { 2 - 3 } \cline { 5 - 7 } & \multicolumn{3}{|c|}{ Погодичный прирост } & & \multicolumn{2}{|c|}{ 22-летний низкочастотный фильтр } \\
\hline Koksu & $\mathbf{0 . 6 8}$ & & & Koksu & 0.54 & & \\
\hline Jelo & $\mathbf{0 . 7 3}$ & $\mathbf{0 . 6 5}$ & & Jelo & 0.62 & 0.58 & \\
\hline Mongun & $\mathbf{0 . 6 6}$ & $\mathbf{0 . 6 2}$ & $\mathbf{0 . 7 5}$ & Mogun & 0.56 & 0.54 & 0.73 \\
\hline N & \multicolumn{3}{|c|}{908} & N & \multicolumn{3}{|c|}{901} \\
\hline
\end{tabular}

Примечание: жирным шрифтом выделены значимые коэффициенты корреляции при $\mathrm{p}<0,05$ для общего периода, когда $\mathrm{EPS} \geq 0.85 ; \mathrm{N}$ - общий объем выборки.

дексов прироста ДКХ Koksu и Tara хорошо коррелируют друг с другом (0.68) и привлеченными ДКХ (0.62-0.73). Высокие значения коэффициентов корреляции между ДКХ Jelo и Tara (0.73) объясняются тем, что данные хронологии находятся недалеко друг от друга (в пределах 50 км). Наименьшие значения коэффициентов корреляции (0.62) показывают ДКХ Koksu и Mongun, наиболее удаленные друг от друга (около 230 км), т.е. с увеличением расстояния усиливаются различия в условиях произрастания. Анализ низкочастотной составляющей индексов прироста показал, что в этом случае происходит общее снижение силы связи как между хронологиями Koksu и Tara (0.54), так и с ДКХ Jelo и Mogun (0.54-0.62).

Сравнение изменчивости прироста ДКХ Koksu и Tara с ДКХ Jelo и Mogun продемонстрировало, что, несмотря на общую согласованность хода кривых в отдельные периоды, отмечается ряд расхождений (рис. 4). Так, например, если в первой половине XV в. у ДКХ Jelo и Mogun происходит подъем, то у ДКХ Koksu и Tara наблюдается падение прироста; в период с конца XVIII по первую половину XIX в. у ДКХ Jelo и Mogun снижение прироста приходится на конец XVIII - первую треть XIX в., а у ДКХ Koksu и Tara - на середину XIX в. Различия в поведении кривых прироста прослеживаются и в конце XX - начале
XXI в., у ДКХ Koksu, Jelo и Mogun отмечается положительный тренд на увеличение прироста (рис. 2 и 4), что хорошо согласуется с результатами, полученным по высокогорным районам Китая (Zhang et al., 2014). В то же время у хронологии Тага наблюдается тренд на снижение прироста (рис. 2 и 4). Учитывая, что данный участок расположен на территории, испытывающей недостаток осадков, эту тенденцию можно соотнести с трендом на снижение количества осадков, характерным для Северной Монголии (Pederson et al., 2014).

Для получения дополнительной палеоклиматической информации, свидетельствующей о происходивших в прошлом экстремальных климатических событиях, был выполнен поиск и анализ распределения повреждений структуры годичного кольца и выпавших колец (рис. 3). На образцах, отобранных с участка Tara, было обнаружено 86 выпавших колец и 167 патологий: 34 морозобойных (f) и 5 светлых (l) колец, 1 флюктуация древесины (fl), 13 разломов (c) и 114 патологических смоляных ходов. На образцах с участка Koksu было найдено 121 выпавшее кольцо и 72 патологии: 7f, 21, 6c и 57 патологических смоляных ходов.

Для выделения экстремальных событий, происходивших в прошлом, по каждому участку были выделены годы, на которые пришлись два и более случая совпадений на- 
рушения структуры или выпавших годичных колец (далее по тексту в скобках приводится число совпадений и вид нарушений структуры годичного кольца). На участке Koksu проведенный анализ патологий в структуре годичного кольца позволил выделить два экстремальных события: 1783 (2f) и 1797 (2f) гг., которые представлены морозобойными кольцами (рис. 3a). Анализ выпавших колец выявил 24 даты: 1570 (2), 1698 (3), 1700 (2), 1743 (2), 1746 (2), 1768 (2), 1775 (6), 1784 (5), 1788 (5), 1801 (4), 1814 (8), 1835 (4), 1840 (7), 1843 (4), 1847 (5), 1850 (2), 1852 (2), 1854 (3), 1869 (3), 1871 (2), 1884 (2), 1917 (3), 1919 (4), 1927 (3) гг. Общих дат совпадения патологических структур и выпавших колец внутри участка не отмечается. В одном случае фиксируется расхождение в один год между датой образования морозобойных (1783 г.) и выпадающих колец (1784 г.). Следует отметить, что морозобойный 1783 г. на Алтае был выделен ранее в работе Н.И. Быкова (2000). Наиболее вероятно, что дата появления морозобойного кольца связана с последствиями извержения вулкана Лаки (1783 г., VEI = 4). Исходя из того что время существования сульфатного аэрозольного слоя в стратосфере составляет не менее 1-2 лет (Oman et al., 2006), это объясняет выпадение колец у деревьев в последующий после извержения год.

На образцах с участка Тага было найдено шесть экстремальных событий (дат совпадения нарушения структуры годичного кольца), пришедшихся на 1222 (2f), 1272 (2f), 1509 (2f), 1695 (1f, 1c), 1812 (2f), 1910 (2c) гг., представленных в основном морозобойными кольцами (рис. 3б). Анализ распределения выпавших колец на этом участке позволил выделить 20 дат: 1259 (2), 1272 (2), 1307 (2), 1319 (2), 1371 (2), 1466 (2), 1481 (2), 1534 (2), 1536 (3), 1658 (2), 1662 (5), 1668 (4), 1699 (3), 1700 (3), 1703 (2), 1705 (2), 1714 (2), 1860 (2), 1864 (2), 1885 (2) гг.
Сопоставление найденных на участке патологий структуры годичного кольца и выпавших колец выявило только один случай их совпадения -1272 г.

Сравнение дат экстремальных событий между участками Tara и Koksu показало отсутствие общих дат совпадения патологий. В нашем случае такое разногласие во времени образования патологий на относительно близко расположенных участках (90 км) можно объяснить экспозиционными отличиями, приводящими к сдвигу в сроках начала и окончания вегетационного сезона и к различиям в условиях увлажнения (как правило, на южных склонах снега лежит в несколько раз меньше). Например, согласно данным табл. 1, если на участке Tara значимое отрицательное воздействие оказывают апрельские среднемесячные температуры (юго-западный склон прогревается раньше), то на Koksu (склон северной экспозиции) фиксируется отклик только на майские.

Анализ распределения выпавших колец определил, что на участках Koksu и Tara отмечается только одна дата их совпадения, приходящаяся на 1700 г. (рис. 4а). Основное количество выпавших колец на участке Koksu отмечается в XVIII-XIX вв., при этом можно выделить и более дробные периоды: 1698-1702, 1740-1802, 1813-1856, 1868-1873, 1916-1927 гг. На участке Tara на общем фоне выделяются четыре периода увеличения количества выпадающих колец: 1658-1669, 1698-1706, 1836-1872, 1885-1888 гг. Таким образом, одновременный рост числа выпадающих колец на обоих участках приходится на конец XVII - начало XVIII в., вторую-третью четверти XVIII в., т.е. на две самые выраженные депрессии прироста, когда воздействие лимитирующего фактора на прирост деревьев было максимально (для периода, где $\mathrm{EPS} \geq 0.85$ ). 


\section{Заключение}

В статье представлены результаты анализа двух новых тысячелетних древеснокольцевых хронологий: Tara - протяженностью 1217 лет (Южно-Чуйского хребет) и Koksu - длительностью 1424 г. (Катунский хребет). Проведенный расчет функции отклика установил, что основное воздействие на радиальный прирост ДКХ Koksu оказывают июнь-июльские, а ДКХ Tara - июньские температуры.

Проведенный анализ патологий в структуре годичного кольца на участке Koksu позволил выделить два экстремальных события: 1783 (2f) и 1797 (2f) гг., представленных морозобойными кольцами. Анализ выпавших колец выявил 24 даты, общих дат совпадения патологий структур и выпавших колец внутри участка не отмечается. На образцах с участка Tara было найдено четыре даты совпадения нарушения структуры годичного кольца - 1222 (2f), 1272 (2f), 1509 (2f), 1695 (1f, 1r) гг., которые в основном представлены морозобойными кольцами. Анализ распределения выпавших колец на этом участке позволил выделить 20 дат. Сопоставление выделенных патологий структуры годичного кольца и выпавших колец выявило только один случай их совпадения - 1272 г. Сравнение дат образования патологий в структуре годичного кольца между ДКХ Tara и Koksu продемонстрировало, что общих закономерностей в их распределении не прослеживается и есть только одна общая дата совпадения, приходящаяся на 1700 г. Такое кардинальное различие времени образования патологий и выпавших колец на относительно близко расположенных участках (90 км) можно объяснить экс- позиционными отличиями, приводящими к расхождению в сроках наступления и окончания вегетационного сезона. Анализ распределения выпавших колец на этих двух участках также показал, что одновременное увеличение числа выпавших колец на обоих участках приходится на два периода: конец XVII - начало XVIII в., вторая - третья четверти XVIII в., т.е. на две самые сильные депрессии прироста, когда воздействие лимитирующего фактора (температуры) на прирост деревьев максимально (для периода, где $\mathrm{EPS} \geq 0.85$ ).

Графическое сравнение изменчивости прироста ДКХ Koksu и Tara с ДКХ Jelo и Mongun выявило, что кривые прироста хорошо согласуются на всем протяжении. Рассогласование отмечается в первой половине $\mathrm{XV}$ в., когда у ДКХ Jelo и Mogun происходит возрастание, а у ДКХ Koksu и Tara - снижение прироста; в период с конца XVIII по первую половину XIX в., когда у ДКХ Jelo и Mogun сильное снижение прироста приходится на конец XVIII - первую треть XIX в., а у ДКХ Koksu и Tara - на середину XIX в. Различия в поведении кривых прироста прослеживаются и в конце XX - начале XXI в. У ДКХ Koksu, Jelo и Mogun отмечается положительный тренд на увеличение прироста, что хорошо согласуется с результатами, полученным по высокогорным районам Китая (Zhang et al., 2014). В то же время у хронологии Tara отмечается тренд на снижение прироста. Учитывая, что данный участок расположен на территории, испытывающей недостаток осадков, эту тенденцию можно соотнести с трендом на снижение количества осадков, характерным для Северной Монголии (Pederson et al., 2014).

Работа поддержсана в рамках проектов РФФИ № 12-06-33040, государственного задания Министерства образования России ФГАОУ ВПО СФУ на 2014 2. (ГВ-1). 


\section{Список литературы}

1. Быков Н.И. (2000) Дендрохронология снежных лавин и циркуляционных процессов атмосферы зимнего и переходного периодов на Алтае. В: Ваганов Е.А., Деревянко А.П., Зыкин В.С. (ред.) Проблемы реконструкции климата и природной среды голоцена и плейстоцена Сибири. Вып. 2. Новосибирск, С. 56-60 [Byikov N.I. (2000) Dendrohronologiya snezhnyih lavin i tsirkulyatsionnyih protsessov atmosferyi zimnego i perehodnogo periodov na Altae. V: Vaganov E.A., Derevyanko A.P., Zyikin V.S. (red.) Problemyi rekonstruktsii klimata i prirodnoy sredyi golotsena i pleystotsena Sibiri. № 2. Novosibirsk, p. 56-60. (In Russian)]

2. Мелехов И.С. (1980) Лесоведение. М: Лесная промышленность, 400 с. [Melehov I.S. (1980) Lesovedenie. M: Lesnaja promyshlennost', 400 p. (In Russian)]

3. Назаров А.Н., Мыглан В.С. (2012) Перспективы построения 6000-летней хронологии по сосне сибирской для территории Центрального Алтая. Журнал Сибирского федерального университета. Биология 5 (1): 70-88 [Nazarov A.N., Myglan V.S. (2012) The possibility of construction of the 6000-Year chronology for Siberian Pine in the Central Altai. Journal of the Siberian Federal University. Biology 5(1): 70-88. (In Russian)]

4. Овчинников Д.В., Ваганов Е.А. (1999) Дендрохронологические характеристики лиственницы сибирской (Larix sibirica L.) на верхней границе леса в Горном Алтае. Сиб. экол. журн 2: 145-152 [Ovchinnikov D.V., Vaganov E.A. (1999) Dendrohronologicheskie harakteristiki listvennicy sibirskoj (Larix sibirica L.) na verhnej granice lesa v Gornom Altae. Sib. jekol. zhurn. 2: 145-152. (In Russian)]

5. Овчинников Д.В., Панюшкина И.П., Адаменко М.Ф. (2002) Тысячелетняя древеснокольцевая хронология лиственницы Горного Алтая и ее использование для реконструкции летних температур. География и природные ресурсы 1: 102-108 [Ovchinnikov D.V., Panjushkina I.P., Adamenko M.F. (2002) Tysjacheletnjaja drevesno-kol'cevaja hronologija listvennicy Gornogo Altaja i ee ispol'zovanie dlja rekonstrukcii letnih temperatur. Geografija i prirodnye resursy 1: 102-108. (In Russian)]

6. Огуреева Г.Н. (1980) Ботаническая география Алтая. М: Наука, 190 с. [Ogureeva G.N. (1980) Botanicheskaja geografija Altaja. M: Nauka, 190 p. (In Russian)]

7. Сухова М.Г., Модина Т.Д. (2007) Современные изменения температурного режима воздуха и режима увлажнения на Алтае, как проявление регионального изменения климата. Мир науки, культуры и образования 2: 14-18 [Suhova M.G., Modina T.D. (2007) Sovremennye izmenenija temperaturnogo rezhima vozduha i rezhima uvlazhnenija na Altae, kak projavlenie regional'nogo izmenenija klimata. Mir nauki, kul'tury i obrazovanija 2: 14-18. (In Russian)]

8. Хантемиров Р.М., Горланова Л.А., Сурков А.Ю., Шиятов С.Г. (2011) Экстремальные климатические события на Ямале за последние 4100 лет по дендрохронологическим данным. Известия РАН. Серия географическая 2: 89-102 [Hantemirov R.M., Gorlanova L.A., Surkov A.Ju., Shijatov S.G. (2011) Extreme climate events on Yamal for the last 4100 years according to dendrochronological data. Izvestija RAN. Serija geograficheskaja 2: 89-102. (In Russian)]

9. Шиятов С.Г. (1986) Дендрохронология верхней границы леса на Урале. М: Наука, 136 с. [Shijatov S.G. (1986) Dendrohronologija verhnej granicy lesa na Urale. M: Nauka, 136 p. (In Russian)] 
10. Шиятов С.Г., Ваганов Е.А., Кирдянов А.В., Круглов В.Б., Мазепа В.С., Наурзбаев М.М., Хантемиров Р.М. (2000) Методы дендрохронологии. Красноярск: КрасГУ, 80 с. [Shijatov S.G., Vaganov E.A., Kirdjanov A.V., Kruglov V.B., Mazepa V.S., Naurzbaev M.M., Hantemirov R.M. (2000) Metody dendrohronologii. Krasnojarsk: KrasGU, 80 p. (In Russian)]

11. Cook E.R., Kairiukstis L. (1990) Methods of dendrochronology: applications in environmental sciences. Dordrecht, Boston, London: Kluwer Acad., 394 p.

12. Cook E.R., Krusic P.J. (2008) A tree-ring standardization program based on detrending and autoregressive time series modeling, with interactive graphics (ARSTAN). http://www.ldeo.columbia. edu/res/fac/trl/public/publicSoftware.html

13. Douglass A.E. (1919) Climatic cycles and tree-growth. A study of the annual rings of trees in relation to climate and solar activity. Washington: Carnegie Inst., $127 \mathrm{p}$.

14. Fritts H.C. (1976) Tree-rings and climate. N.Y.: Academic Press, 576 p.

15. Gurskaya M.A., Shiyatov S.G. (2006) Distribution of frost injuries in the wood of conifers. Russian Journal of Ecology 37 (1): 7-12

16. Holmes R.L. (1983) Computer-assisted quality control in tree-ring dating and measurement. Treering Bulletin 43: 69-78

17. Myglan V.S., Zharnikova O.A., Malysheva N.V., Gerasimova O.V., Vaganov E.A., Sidorova O.V. (2012a) Constructing the tree-ring chronology and reconstructing summertime air temperatures in southern Altai for the last 1500 years. Geography and Natural Resources 33: 200-207

18. Myglan V.S., Oidupaa O.Ch., Vaganov E.A. (2012b) A 2367-year tree-ring chronology for the Altai-Sayan region (Mongun-Taiga mountain massif). Archaeology, Ethnology and Anthropology of Eurasia 40: 76-83

19. Oman L., Robock A., Stenchikov G.L., Thordarson T., Koch D., Shindell D.T., Gao C. (2006) Modeling the distribution of the volcanic aerosol cloud from the 1783-1784 Laki eruption. Journal of Geophysical Research: Atmospheres 111: 1-15

20. Pederson N., Hessl A.E., Nachin B., Anchukaitis K.J., Cosmo N.Di. (2014) Pluvials, droughts, the Mongol Empire, and modern Mongolia. Proceedings of the National Academy of Sciences 111: 4375-4379

21. Rinn F. (1996) TSAP V 3.6 Reference manual: computer program for tree-rings analysis and presentation. Heidelberg: Frank Rinn Distribution, 264 p.

22. Sidorova O.V., Saurer M., Myglan V.S., Eichler A., Schwikowski M., Kirdyanov A.V., Bryukhanova M.V., Gerasimova O.V., Kalugin I., Daryin A., Siegwolf R.T.W. (2012) A multi-proxy approach for revealing recent climatic changes in the Russian Altai. Climate Dynamics 38 (1): 175-188

23. Sidorova O.V., Siegwolf R.T.W., Myglan V. S., Ovchinnikov D.V., Shishov V.V., Helle G., Loader N.J., Saurer M. (2013) The application of tree-rings and stable isotopes for reconstructions of climate conditions in the Russian Altai. Climatic Change 120 (1-2): 153-167

24. Wigley T., Briffa K., Jones P. (1984) On the average value of correlated time series, with application in dendroclimatology and hydrometeorology. J. Clim. Appl. Met. 23: 201 - 213

25. Zhang Y., Shao X.M., Yin Z.Y., Wang Y. (2014) Millennial minimum temperature variations in the Qilian Mountains, China: evidence from tree rings. Clim. Past 10: 1763-1778 